\title{
Evaluating the Impact of Technological Tools on the Academic Performance of English Language Learners at Tertiary Level: A Pilot Investigation
}

\author{
Muhammad Asif ${ }^{1 *}$, Muhammad Sheeraz ${ }^{2}$, Steven J. Sacco ${ }^{3}$ \\ ${ }^{1} \mathrm{PhD}$ Candidate, Department of English, International Islamic University, Islamabad, Pakistan \\ ${ }^{2}$ Assistant Professor, Department of English, International Islamic University, Islamabad, Pakistan \\ ${ }_{3}^{3}$ Professor Emeritus, Department of European Studies, San Diego State University, California, United States,
}

\begin{abstract}
The current investigation aimed to explore how and to what extent technology tools and web-delivered language learning platforms impact the academic performance of English language learners (ELLs) at the tertiary level. The study used a quantitative experimental research method employing a single-group pre-test and post-test design. A total of $N=525$ undergraduate computer science students partook in this research. The participants enrolled in their first semester at the Faculty of Information Technology in a private sector university in Lahore, Pakistan, were selected using a simple random sampling technique. The data were gathered in two phases: a pre-test was administered in the first week, and a post-test was conducted in the sixteenth week. The Reading Comprehension and Use of English assessments adapted from ETS TOEIC - a credible instrument in terms of validity and reliability - were used for this purpose. The investigators applied frequency analysis in the form of percentages to get various descriptive statistics. They utilised Spearman's rank-ordered correlation and Kruskal-Wallis H tests to verify the findings of the descriptive statistics, address the research question and respond to the statistical hypotheses. Despite diverse linguistic and technological barriers, the results revealed a positive impact of technology tools on ELLs' academic performance. The study proposed that taking undergraduates from other disciplines and exploring other variables affecting ELLs' performance and confidence need further consideration.
\end{abstract}

Keywords: Declarative-accelerated blended learning, English language learners, Online learning platforms, Tertiary level, Transparent Language Online.

\section{INTRODUCTION}

With the advent of the technological era, higher education institutions have perceived the need to use new digital and educational technologies most feasibly while living in a world with excellent prospects to converse with practitioners and experts from diverse disciplines, including socially and linguistically contextualised domains (Kessler, 2018; Laurillard, 2013; Lupton et al., 2018; Ng, 2015). Technology, a deeply integrated part of our modern lives, can change how we learn, instruct and communicate in a second language (Özyurt \& Özyurt, 2017; Salehudin et al., 2021) particularly in the present technological era and the computer-savvy generation of students. Technology is not an extravagance for anybody in the current age, yet a fundamental requirement for all; however, its utilisation and access are disproportionately disseminated (Ortega, 2017). Technology is a tool that might affect the language learners and the learning process if not directed efficiently. In the current perspective, technology is a reality, providing every student access to master a language both inside and outside the classroom (Bonner \& Reinders, 2018; Kessler, 2018). Well-established technologies ended up being practically pervasive for imparting instruction in language pedagogy worldwide (Golonka et al., 2014; Levy, 2009; Selwyn, 2013; Steel \& Levy, 2013), contemporary technologies, mobile devices, are progressively accessible to foster L2 learning (Godwin-Jones, 2017; Ko, 2017; Lin \& Lin, 2019; Loewen et al., 2019, 2020), yet other technologies, web-delivered learning platforms, virtual reality (VR) and mobile apps are still emerging (Bonk \& Wiley, 2020; Parmaxi, 2020; Yang \& Kuo, 2020). Researchers have agreed that the best approach to teach and learn languages is to combine technology with human instruction, blended learning, based on its pedagogical techniques blended with technology (Bonk \& Graham, 2006; DeMillo, 2019; Dziuban et al., 2018; Gunes, 2019; Horn \& Staker, 2015; McCarthy, 2016; Stein \& Graham, 2014).

Corresponding Author e-mail: asifabid85@gmail.com https://orcid.org/0000-0003-0076-8717

How to cite this article: Asif M, Sheeraz M, . Sacco SJ (2022). Evaluating the Impact of Technological Tools on the Academic Performance of English Language Learners at Tertiary Level: A Pilot Investigation. Pegem Journal of Education and Instruction, Vol. 12, No. 1, 2022, 272-282

Source of support: Nil

Conflict of interest: None.

DOI: $10.47750 /$ pegegog. 12.01 .28

Received: 11.10 .2021

Accepted: 18.12 .2021
Publication: 01.01 .2022 
This study neither includes all the existing educational technologies, web-delivered learning platforms, and learning apps being used for teaching and learning languages nor uses fully online or face-to-face mode; regardless, the study is limited to the use and impact of Transparent Language Online (TLO) and Learning Management System (LMS) using blended learning approach and its impact on ELLs' accomplishments. The investigation also sets the stage for exploring the declarative-accelerated blended learning (DABL) approach - a blend of technology with pedagogy - and its significance in the teaching-learning process. DABL, an optimal TLO technique for learning languages, grounded itself on a cardinal principle of human learning. Modern functional magnetic resonance imaging (fMRI) has shown that the human brain has two memory systems that add to language learning: declarative and procedural; the declarative memory system learns facts, whereas the procedural memory system learns skills (Ullman, 2001). Out of these two, the former plays a considerably more crucial role in learning a language than the latter that encourages learning aptitudes.

To improve the communication skills of their students, universities in Pakistan are designing their curricula blending English language instruction with advanced educational technologies as an apparatus befitting to learn the target language inside and outside the classroom (Quraishi et al., 2020). For this purpose, higher education institutions in Pakistan have been putting resources in the growing domain of educational technology (Shehzadi et al., 2021) by providing outstanding learning platforms to improve learners' academic performance in L2. Learners face diverse technological and linguistic limitations upon entering an undergraduate program at the tertiary level in Pakistan, which, to some extent, affects the learning process. Technological advancements, at their best, can uphold learners' inquisitiveness and stimulate them to strengthen their core language skills; prescribe their expanding access to L2 input and feasible shared opportunities; provide educators with a conducive method to plan, design, and implement course content and collaborate with mixed-ability learners in synchronous and asynchronous environments.

The significance of the current investigation lies in the fact that language learning augmented by digital tools is helpful for ELLs to develop their integrated language skills and increase their confidence when interacting with web-delivered learning platforms that provide ample opportunities to accelerate L2 learning. These technological facilitations have encouraged learners to practice and master any second language "anywhere, anytime 24/7/365" (Vesselinov et al., 2019, p. 8) and served as trendsetters for cultivating autonomous learning. This implies that learners direct their L2 needs without an educator or a coursebook that generally drives them into learning a second language in a traditional environment.
The present study uses the TPACK framework to help language educators improve their current knowledge, revisit their instructional strategies, cater to ELLs' learning needs, and upgrade the course curriculum to meet 21 st-century demands. TPACK includes a blend of assimilated technological knowledge (TK), content knowledge (CK), and pedagogical knowledge (PK) (Koehler et al., 2013; Mishra \& Koehler, 2006; Rosenberg \& Koehler, 2015)now known as TPACK, or technology, pedagogy, and content knowledge; and its transformative nature helps in integrating advanced digital tools in L2 by educators' proper training and effort yet additionally embrace the system for effective language practices in synchronous and asynchronous environments. In return, this helps learners instil self-awareness, a crucial factor for self-regulated learning, enables them to take responsibility for their education, identifies their strengths and shortcomings, and facilitates them to become more conscious of their learning path, leading ultimately to higher academic accomplishments. In this regard, technology tools might play a pivotal role in making learners familiarise themselves with the system to improve their performance, acquire better results on the academic assignments and open a gateway to the world academia (Chun et al., 2016; Sharaf \& Musawi, 2011).

The research question of the study is: How and to what extent does the integration of technology tools with pedagogy impact the academic performance of ELLs at the tertiary level?

The research hypotheses of the investigation are:

- $\mathrm{H}_{0}$. There is no significant impact of technology tools on the academic performance of ELLs at the tertiary level.

- $\mathrm{H}_{\mathrm{a}}$. There is a significant impact of technology tools on the academic performance of ELLs at the tertiary level.

\section{Research Method Research Design}

This investigation used a quantitative experimental research method employing a single-group pre-test and post-test design. This method was used for this study keeping in mind its distinctive features related to quantitative and experimental techniques, for instance, beginning with explicit hypotheses, gathering quantifiable data related to presumptions, and afterwards employing statistical methods by examining as well as extrapolating the data (Creswell \& Creswell, 2018; Leedy \& Ormrod, 2016; Riazi, 2016).

\section{Participants}

The total participants, $N=573$, were selected using a simple random sampling technique. A G*Power version 3.0.10 was utilised to determine the sample size (Faul et al., 2007, 2009). The participants were enrolled at the Faculty of Information Technology undergraduate program in a private sector university in Lahore, Pakistan, who studied Functional English 
as a mandatory course in their first semester. They were equally distributed into thirteen (13) Functional English sections titled A - M, mainly comprising 45 students each. Nonetheless, some of the students withdrew and did not participate in the pre-test and the post-test; others dropped out of the program. Subsequently, the students reliably partaking in the program stayed $N=525$.

\section{Learning Systems}

The learning system's three principal components facilitated ELLs: TLO, LMS, and the cloud. TLO was used to impart instruction in the English language, LMS mostly controlled graded assessment, learning activities, data and analytic generation, and the cloud helped store and accommodate the data (content, assessment, and learning progress reports). The study used a blended model and empowered ELLs to learn and explore Transparent Language Online in synchronous and asynchronous environments to strengthen their integrated language skills. However, assessments were administered on LMS and strictly observed in synchronous mode, with no access to mobile devices, internet connectivity, and shuffled tests' questions and items option, to ensure effective implementation and avoid cheating.

\section{Transparent Language Online}

Transparent Language Online (TLO) is a web-delivered teaching and learning platform based in New Hampshire, United States. TLO presents dozens of learning encounters per minute, observes and records learning outcomes, and continually adjusts until the learners commit the material in their declarative memory. TLO provides a robust learning environment that incorporates both asynchronous preparations using the web, computer, or mobile capabilities (place anywhere anytime) and synchronous conversations, role-play, and inlanguage tasks (occur in the conventional environment). The instruction was predominantly offered through TLO's platform, where students were assigned twenty-eight units, two lessons per week, each unit/ lesson consisting of four learning activities and one assessment. With TLO's lesson authoring feature, language educators developed and customised in-house content as per ELLs' needs. The university purchased licensed user accounts for each enrolled student in advance.

\section{Learning Management System (LMS)}

A group of in-house designers developed the LMS subsystem on a Moodle View Controller (MVC) design. LMS was predominately established and used to administer learning activities and varied assessments, gather data, make in-situ analytics, and generate ELLs' progress reports for various stakeholders. The varied examinations (pre-test, 4assessments/ quizzes, and post-test) were administered using LMS during a 16-week semester. Individual LMS user accounts were generated for each student, and they were provided with login information to access the system. The analytic feature was enabled in each user account and accessible through the intelligent propagation subsystem. The concerned stakeholders received the email right after a broad range of analytics were created.

\section{Data Collection Tools and the Process}

The data collection instruments of the present investigation, the Reading Comprehension and Use of English (RC\&UoE) assessments, were adapted from ETC TOEIC, credible instruments in terms of validity and reliability (Chapman \& New fields, 2008; Powers et al., 2008; Suzuki \& Daza, 2004; Wilson, 2000)at least in business contexts. According to a 2008 Japan Institute of Lifelong Learning report, $64 \%$ of the 162 universities colleges in Japan described in their study use the TOEIC for streaming incoming students - a use for which this test was never designed. Moreover, in line with MEXT's (2003. Each assessment contained 42 test items to be attempted in 40 minutes, and automated feedback was shared in students' scores and graphs with both teachers and students. The 42 test items were subdivided into grammatical and lexical constructs, including noun, pronoun, adjective, verb, adverb, preposition, conjunction, subject-verb agreement, phrase, clause, negatives, and vocabulary - the undergraduate students, generally focused on at the computer science faculty.

This pilot experiment was conducted in an observed synchronous environment in two phases: a pre-test and a post-test. The experiment lasted for sixteen (16) weeks, whereas pedagogical practices continued for fourteen (14) weeks, consisting of 45-48 lectures of 90 minutes each in a four (4) credit hour course. Students used computer labs for the English language, where each student was provided separate login to their PCs and TLO/LMS systems to access their dashboard and learning path. The students could access the content synchronously and asynchronously and follow their own pace to work on each task. They completed twenty-eight units from TLO's English in Context. Overall, six (06) assessments (a pre-test, 4-assessments, and a post-test) were administered on LMS, automated checked by the system, to analyse ELLs' learning progress. However, this experiment is restricted to ELLs' performance on the pre-test and post-test.

A pre-test was administered in the first week. The results were communicated with various stakeholders, including students, educators, and administration, which unveiled ELLs' background knowledge and spotlighted learners' linguistic limitations and self-directed learning. This helped language educators to readjust the content and understanding activities in the pre-defined curricula as per ELLs' needs. After the pretest, ELLs started their regular semester classes and attempted varied graded assessments during a 16-week semester. A post-test was administered in the last week of the semester, 
and again the results were shared with the stakeholders. The post-test results were compared with the pre-test results to evaluate ELLs' performance on different constructs. A master data spreadsheet was generated in Microsoft Excel comprising data of thirteen sections and was imported to IBM SPSS 25.0 to examine descriptive and inferential statistical analyses. Graphical representation of the assessment was shared for facilitation to analyse ELLs' accomplishments.

\section{Data Analysis}

The data obtained were analysed by SPSS 25.0 program. The researchers applied frequency analysis in the form of percentages to get various descriptive statistics and checked normality assumptions. After attaining descriptive statistics and satisfying normality requirements, the decision was taken into consideration to use a non-parametric method to gather, examine, decipher and report information because the data were not normally distributed, and it did violate parametric assumptions. Studies have shown that non-parametric tests are typically proposed for the investigation of ordinal or nominal data (Corder \& Foreman, 2009; Field et al., 2012; Larson-Hall, 2015; Loewen \& Plonsky, 2016; Plonsky, 2015), they are ideally benefitted for the proper use in humanities and social science research. Thus, the investigators utilised Spearman's rankordered correlation coefficient to observe the discrepancies among all thirteen sections and examine the relationship among different lexical and grammatical constructs (error types). Likewise, they applied the Kruskal-Wallis $\mathrm{H}$ test for one-way analysis of variance (ANOVA) by ranks to corroborate Spearman's correlation coefficient's results, address the research question and respond to the statistical hypotheses.

\section{Results}

This section presents a methodical investigation of the data from a pre-test and post-test that measured ELLs' performance of various constructs in all sessions. The results are deciphered and illustrated through graphs, histograms, scatterplots, and tables. The research question of the current study has been addressed using descriptive and inferential statistical analysis concentrating on how and to what does the integration of technology tools with pedagogy impact the academic performance of English language learners at the tertiary level. The researchers also investigated the null and alternative hypotheses, i.e., $\mathrm{H}_{0}$ and $\mathrm{H}_{\mathrm{a}}$.

\section{Descriptive Analysis}

Frequency analysis was applied in the form of percentage to get descriptive statistics while deciding on all constructs that presented the details and provided the comparative study of pre-test and post-test in the form of error-wise, section-wise, error-wise observed improvement, and section-wise observed improvement.

\section{Error-wise Comparative Analysis}

Figure 1 illustrates the aggregate proportion of various errors students made and its' occurrence dispersed disproportionately among the stated error types. In any case, the post-test demonstrated better results when compared to the pre-test, yet, while most constructs improved, some worsened. For instance, the participants produced maximum errors in conjunction with $32 \%$ in the pre-test and $51 \%$ in the post-test. Similarly, with pronouns, the number of errors increased from $15 \%$, in the pre-test, to $31 \%$ in the post-test.

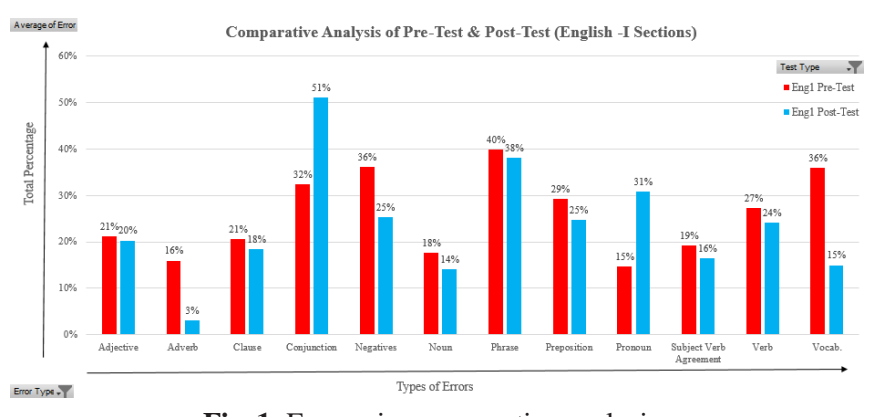

Fig. 1: Error-wise comparative analysis

\section{Section-wise Comparative Analysis}

As shown in Figure 2, the histogram presents an interesting perspective of the data when examined with a tabulated number of errors made separately in each section, for instance, an average of the number of errors produced in each learning construct by each division. Most sections improved the lexical and grammatical constructs by having minimum errors and using the items appropriately; however, few areas stayed at the same level or even worsened. Most noticeably, the worst results were observed in section $\mathrm{C}$, which had $22 \%$ errors in the pretest that increased to $26 \%$ in the post-test. Sections $\mathrm{G}$ and I remained the same at $25 \%$ and $27 \%$, respectively, in both tests, which was surprising because semester-long treatment was administered. After the post-test, the researchers anticipated to observe a reduction in erroneous responses.

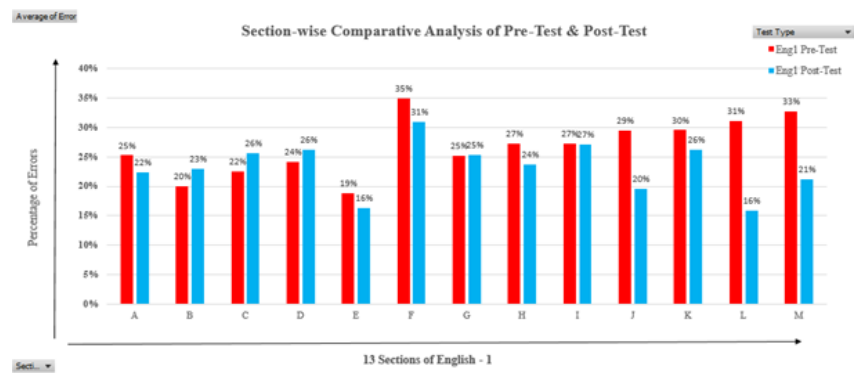

Fig. 2: Section-wise comparative analysis

\section{Error-wise Observed Improvement}

As shown in Figure 3, the researchers plotted data of all sections to identify the problematic constructs. The histogram 
shows that students improved in maximum constructs whereas demonstrated worse results in conjunction and pronoun as $-57.4 \%$ and $-109.3 \%$ in error production, respectively.

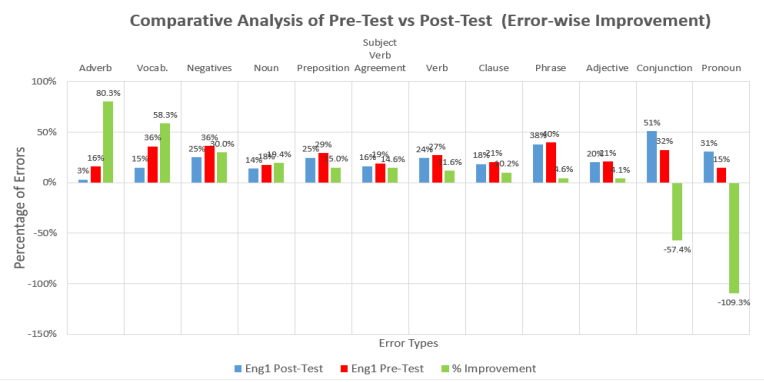

Fig. 3. Error-wise observed improvement

\section{Section-wise Observed Improvement}

Figure 4 shows section-wise observed improvement with variations among all sections in the two tests. In total, eight instructors taught thirteen sections, and four among them taught multiple sections. Most of the sections performed better and showed improvement, for example, A, E, F, H, J, K, L and M as $11.5 \%, 13.4 \%, 11.5 \%, 12.7 \%, 33.4 \%, 11.2 \%, 49.0 \%$ and $35.3 \%$, respectively. Some sections, taught by the same instructor, illustrate different results. For instance, sections $\mathrm{B}$ and $\mathrm{F}$ portray extreme results: section B worsened (-15\%), whereas F showed improvement (11.5\%) compared to the post-test results. Simultaneously, sections D, J, and M performed differently. For example, section $\mathrm{D}$ worsened (-8.5\%), while $\mathrm{J}$ and $\mathrm{M}$ demonstrated improvement $(33.4 \%, 35.3 \%$, respectively). Upon interviewing the instructors of these sections about ELLs' poor performance, the researchers proposed additional technical and linguistic training to accelerate ELLs' language use.

The findings of the descriptive statistics examined, approved and accepted the alternative hypothesis for the research question by showing a significant impact of technology tools on the academic performance of ELLs at the tertiary level. The investigators applied different inferential statistical tests to verify the findings of the descriptive statistics, re-examine the alternative hypothesis, i.e., $\mathrm{H}_{\mathrm{a}}$ and address the research question.

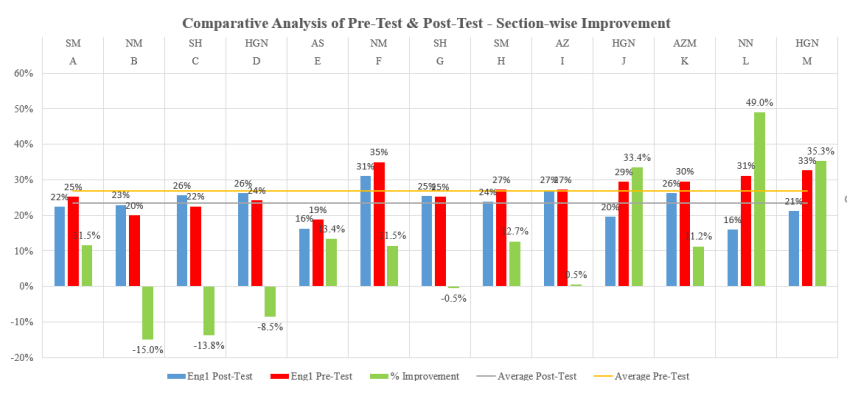

Fig. 4: Section-wise/ teacher-wise observed improvement

\section{Spearman's Rank Ordered Correlation}

For further analysis, the data were subjected to Spearman's rank-ordered correlation test (Zar, 2014). The distributions produced by the pre-test revealed that all the sections were strongly correlated with each other. It was expected since the total sample partook in this experiment and belonged to the same population of the undergraduate (computer science) program from Pakistan with technical and linguistic limitations. The weakest correlation was between sections J and $\mathrm{K}$ in the pre-test, which turned out to be a robust correlation at the end of the experiment $(r s=0.82, p<.001)$.

Moreover, section $\mathrm{H}$ and I present the strongest correlation $(\mathrm{rs}=0.99, \mathrm{p}<.001)$ with almost approaching to reach $100 \%$.

It has been observed that after the application of the intervention, the correlation among different sections reduced in general. The minimum strength correlation was between sections $\mathrm{C}$ and $\mathrm{L}$ ( $\mathrm{rs}=0.67, \mathrm{p}<.001$ ), and maximum strength correlation was between section $\mathrm{G}$ and $\mathrm{H}(\mathrm{rs}=0.99, \mathrm{p}<.001)$. Nevertheless, this was unexpected since all learners who were at first highly correlated had lost their capability of moving together in one direction, and reduced correlation has been observed in the post-test. This situation was alarming. The researchers speculated that language educators' discrepancies and sections held at a different time of the day (morning, afternoon, evening) had been assumed as the unknown reasons.

Moreover, some instructors taught multiple sections; the researchers investigated the change of correlation from pre-test to post-test among their respective sections. The correlation between sections $\mathrm{A}$ and $\mathrm{H}$, led by the same instructor, was observed as ( $r s=0.97, \mathrm{p}<.001)$ in pre-test that plummeted to $(\mathrm{rs}=0.92, \mathrm{p}<.001)$ in post-test. Figure 5 shows the correlation between sections $\mathrm{A}$ and $\mathrm{H}$ in pre-test and post-test. The fit line shows the trend, which is always positive and strong.

As shown in Figure 6, the scatterplot portrays the correlation between sections $\mathrm{B}$ and $\mathrm{F}$ in pre-test and post-test which was at first $(\mathrm{rs}=0.93, \mathrm{p}<.001)$ plunged to $(\mathrm{rs}=0.73, \mathrm{p}$ $<.001)$ in the post-test.

As illustrated by Figure 7, the scatterplot exhibits the correlation between sections $\mathrm{C}$ and $\mathrm{G}$ underscored ( $\mathrm{rs}=0.96, \mathrm{p}$ $<.001)$ in the pre-test fell to $(\mathrm{rs}=0.79, \mathrm{p}<.001)$ in the post-test.

Figure 8 shows the scatterplot of correlation in sections D, $\mathrm{J}$, and $\mathrm{M}$ taught by the same educator. The correlation between $\mathrm{D}$ and $\mathrm{J}$ was observed as $(\mathrm{rs}=0.84, \mathrm{p}<.001)$ in the pre-test which increased to $(r s=0.93, p<.001)$ in the post-test. While sections $\mathrm{D}$ and $\mathrm{M}$ had ( $\mathrm{rs}=0.91, \mathrm{p}<.001)$ in the pre-test which reduced to ( $r s=0.85, \mathrm{p}<.001)$ in the post-test. Finally, sections $\mathrm{J}$ and $\mathrm{M}$ had ( $\mathrm{rs}=0.92, \mathrm{p}<.001)$ at first, which stayed the same in the post-test as $(r s=0.92, p<.001)$.

As shown in Table 1, the correlation between each section's pre-test and post-test was a tertiary perspective to examine ELLs' academic performance. The researchers assumed that Pegem Journal of Education and Instruction, ISSN 2146-0655 


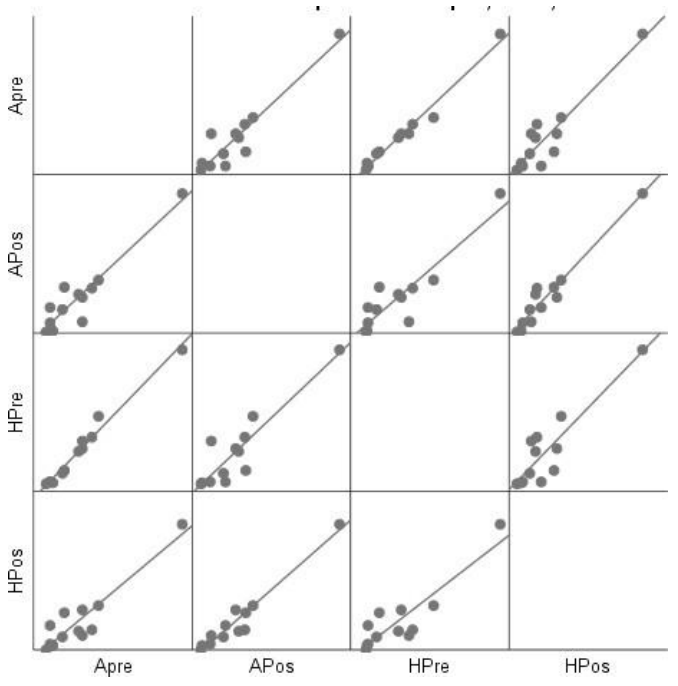

Fig. 5: Scatterplot of all possible correlations between sections $\mathrm{A}$ and $\mathrm{H}$

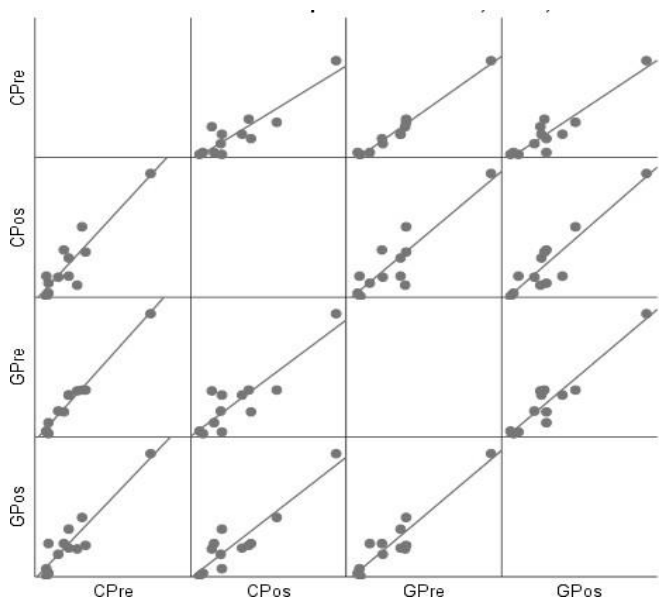

Fig. 7: Scatterplot of all possible correlations between sections $\mathrm{C}$ and $\mathrm{G}$

Table 1: Spearman's correlation coefficient (Rho)

\begin{tabular}{ll}
\hline Section & rho \\
\hline A & 0.8 \\
B & 0.87 \\
C & 0.7 \\
D & 0.73 \\
E & 0.8 \\
F & 0.78 \\
G & 0.72 \\
H & 0.79 \\
I & 0.87 \\
J & 0.7 \\
K & 0.7 \\
L & 0.75 \\
M & 0.84 \\
\hline
\end{tabular}

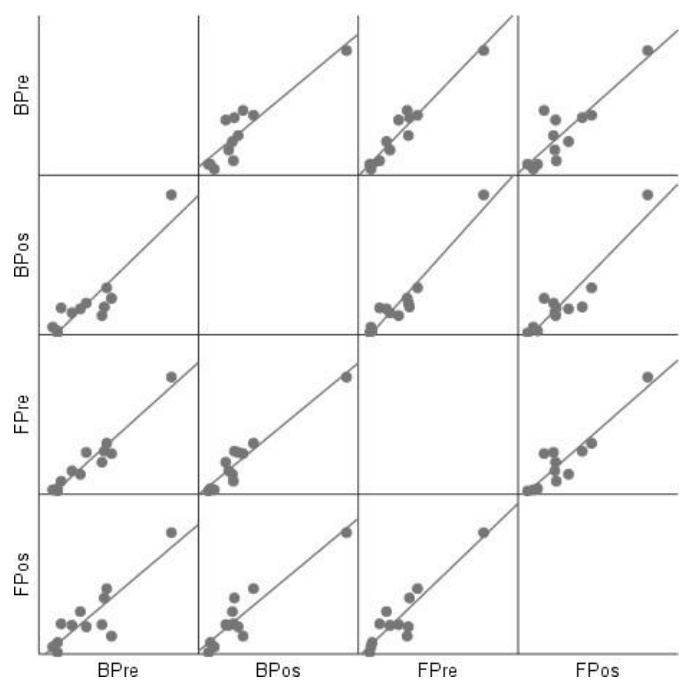

Fig. 6: Scatterplot of all possible correlations between sections B and $F$

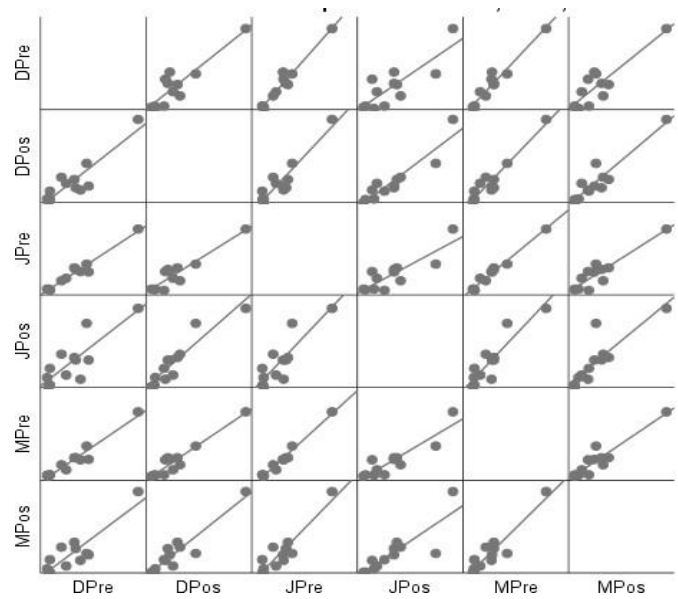

Fig. 8: Scatterplot of all possible correlations of sections D, J, And M

ELLs might demonstrate a reduction in error-types in the post-test; nonetheless, their expectations were not met and the correlation, however, displays a slight decline compared to correlations from other sections, were still significantly strong. The following table shows that Spearman's correlation coefficient (rho) was computed between the pre-test and posttest distributions for all thirteen sections.

Summing up the correlation analysis, the re- searchers observed that reducing correlations in- ferred that not all thirteen sections move together in the same fashion throughout the experiment. The pattern of making mistakes changed through the course of the semester. Besides, no significant dissimilarities were witnessed in the sections being trained by different instructors. 


\section{Kruskal-Wallis H Test for One-way Analysis of Variance (ANOVA) by Ranks}

To double-check the results of Spearman's rank-ordered correlation, the researchers used the Kruskal-Wallis $\mathrm{H}$ test for non-parametric one-way analysis of variance (ANOVA) among all sections instructed by multiple instructors $(\chi 2(7)$ $=3.93, \mathrm{p}>.05)$. The boxplot in Figure 9 portrays the marginal distributions of pre-test pertaining to instructors in each section and displays that $\mathrm{H}$-statistics rejected $\mathrm{HO}$ of discrepancies in the sample. Besides, the circles represent outliers.

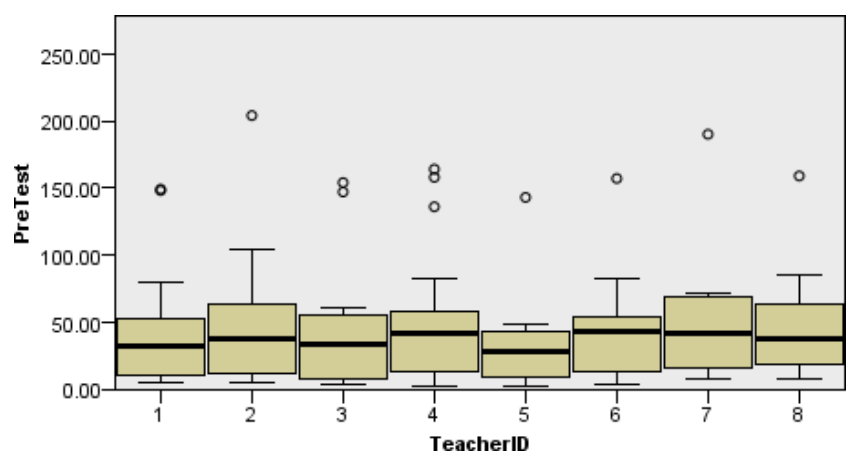

Fig. 9: Scatterplot of marginal distributions of pre-test categorised pertaining to educators in each section

As shown in Figure 10, the means in the distributions of post-test floated; nonetheless, the hypothesis of the sample coming from a diverse population was still not accepted $(\chi 2(7)=5.93, p>.05)$. The scatterplot illustrates marginal distributions of post-test pertaining to instructors in each section. The circles show outliers, and asterisks (*) represent extreme outliers.

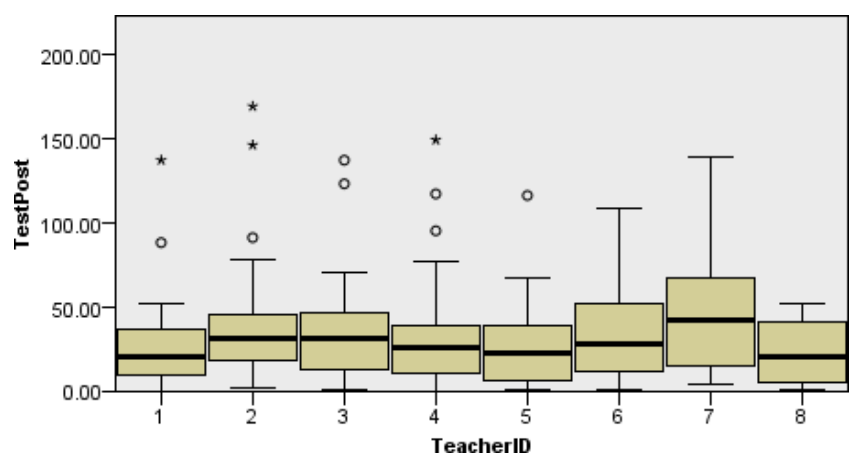

Fig. 10: Scatterplot of marginal distributions of post-test categorised pertaining to educators in each section

Another speculation was the different class timings (morning, afternoon, evening) may contribute to ELLs' academic performance. The researchers assumed that ELLs who are taking classes early morning might feel fresh and more enthusiastic and consequently perform better than learners who are taking classes later afternoon or evening might feel exhausted and unable to concentrate. To test this hypothesis, the investigators executed Kruskal-Wallis' oneway

ANOVA by categorising the sections based on their schedule. The independent variable, namely TimeID, could have one of the four potential values. One represented the early morning slot, two signified 11:00 am slot, three denoted afternoon time window, and four demonstrated evening slot. The Kruskal- Wallis' one-way ANOVA retained the null hypothesis that all the distributions belong to one population and that there was no significant difference in the means $\left(\chi^{2}\right.$ (3) $=1.81, \mathrm{p}>$

$.05)$. Nonetheless, when the test was executed with the same values of TimeID on the post-test, the $\mathrm{H}$-statistics retained the null hypothesis, inferring that no significant difference was observed among different classes (sections) $(\chi 2(3)=3.67, \mathrm{p}>$ $.05)$.

Figure 11 and Figure 12 show the scatterplots of pre-test and post-test. Figure 11 presents the marginal distribution of pre-test categorised pertaining to different sections' schedule (when the class was held). The circles and asterisks portray outliers and extreme outliers.

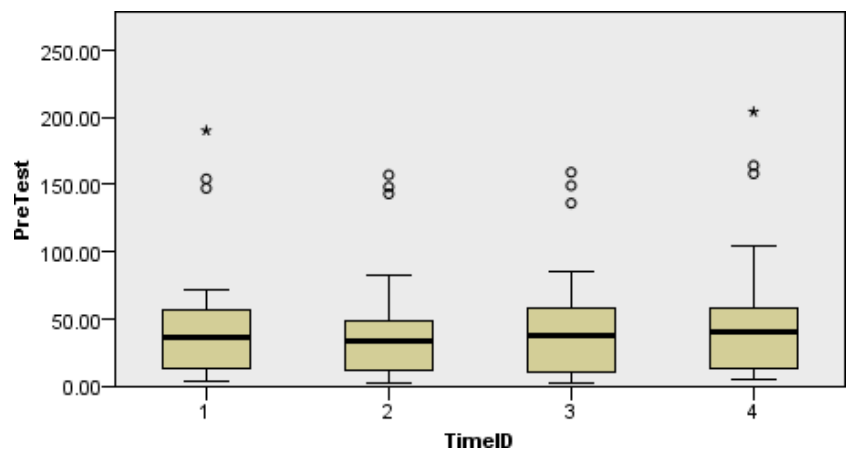

Fig. 11: Scatterplot of marginal distributions of pre-test categorised pertaining to schedule to different sections

Figure 12 demonstrates the marginal distribution of posttest categorised about different sections' schedule (when the class was held). The circles and asterisks portray outliers and extreme outliers.

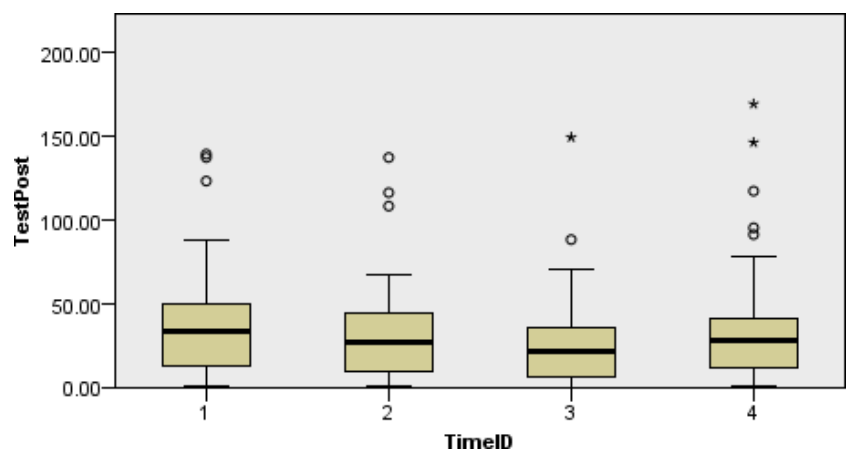

Fig. 12: Scatterplot of marginal distributions of post-test categorised pertaining to schedule to different sections

Both Spearman's rank-ordered correlation and Kruskal-

Pegem Journal of Education and Instruction, ISSN 2146-0655 
Wallis $\mathrm{H}$ test for one-way analysis of variance by ranks validated the results of each other and verified the alternative hypothesis presenting a significant impact of technology tools on the academic performance of ELLs at the tertiary level.

\section{Discussion}

This section explicates the overall impact of technology tools on ELLs' academic accomplishment, determined through their pre-test and post-test performance. This inclusion of educational technologies expedited the learning process, whichELLs indicated was adaptable, unbiased, and offered timely evaluation on the varied assessments. This has implications for designing the assessments, restructuring the curriculum and instructional approach as per ELLs' needs, and providing practical training to educators and learners alike. First, this pilot investigation revealed that most sections improved maximum grammatical and lexical constructs, whereas the performance of a few sections worsened. Upon investigating the weaker sections, $\mathrm{C}$ and D $(N=90)$, ELLs' comments revealed that most of them came from diverse cultures and demonstrated linguistic and technological limitations having no prior association with the English language or available technology tools.

Nonetheless, the learners also reported language barriers pertaining to language use and accuracy, level of difficulty of certain test items, and content of the tasks. The researchers readjusted or removed certain items creating intelligibility problems for the learners. They likewise mentioned that their concerned instructors did not encourage them to use accessible digital tools and imparted instructions through typical traditional strategies using the whiteboard, pen, paper, and pre-planned prepared notes. Besides, the histograms are corroborated by ELLs' performance on the academic tasks, their increased ability, confidence, and frequency to apply English language knowledge in an adaptable, spontaneous, and diverse environment. Simultaneously, the results proved the alternative hypothesis $\left(\mathrm{H}_{\mathrm{a}}\right)$ and found a significant impact of technology tools on the academic performance of ELLs at the tertiary level. The findings also showed a substantial difference in ELLs' academic performance and increased confidence in using English in a diverse environment.

Second, the pilot experiment validated the instruments and restructured the pre-designed course curriculum as per 21 st-century learners' needs. Instructors were adequately trained on how to use TLO's lesson authoring feature and customise the lessons accordingly. They were discouraged from using already prepared notes or traditionally imparting instruction.

Moreover, this study's results illustrated that the best way to teach a second language is to integrate technology with realtime, face-to-face instruction. Research suggests that a blended learning model is the best solution to cater to L2 learners' needs

Pegem Journal of Education and Instruction, ISSN 2146-0655
(DeMillo, 2019; Dziuban et al., 2018; Gunes, 2021; Horn \& Staker, 2015; Madden et al., 2019; McCarthy, 2016).

Third, the classroom observations and meeting with all thirteen sections underscored that the instructor is the ship captain. Without their willingness to integrate advanced technology tools, the whole experiment turned out to be futile.

The results revealed that most instructors who invested time in learning technology tools and training ELLs, their sections performed much better than those who were reluctant to embrace technology. Quraishi et al. (2020) accentuated the significance of teachers' training and continuous professionaldevelopment programs at the tertiary level in Pakistan to ensure the effective implementation of L2 instruction as per $21^{\text {st }}$-century needs.

Finally, the findings are in tandem with the perspective (Baran et al., 2019) that integrating the TPACK framework in teachers' training and continuous professional development (CPD) program will help avoid scrappy workshops, disinclined strategies towards the shift to guarantee ELLs' satisfaction and steadiness of the existing apparatuses. This will facilitate instructors' learning in CPDs, reflecting ELLs' better performance if they effectively execute the learned knowledge.Nevertheless, the researchers shared findings with the authorities, local $\mathrm{PhD}$ supervisor, Director-English, and Faculty-Dean. They explicated the significance of restructuring the already established practised curriculum, mandatory instructors' training and CPD programs linked with annual appraisal, upgrading the existing technology tools, and providing zero semesters to learners with linguistic and technological limitations, where educators work closely with ELLs to acquaint them with the system. This experiment helped the administration and the English language instructors of the concerned faculty to accentuate ELLs' performance bearing in mind the mentioned recommendations.

\section{Conclusion}

The educational technology tools improved ELLs' performance on the academic assignments, contributed to their inquisitiveness, and increased confidence while using English language at the tertiary level. This additionally expounds that technology tools, when integrated and used effectively, increased ELLs' learning outcomes, helped them expand their horizon, and demonstrated better results, as validated by findings. The results showed that technology,

on account of its speed, adaptability, and customisation, successfully teaches the declarative component of language. A computer can display many learning encounters per minute, identify and report outcomes, and persistently adjust until they store the learning material in their declarative memory. In this regard, using Transparent Language Online, improved ELLs' performance has been observed on the pre-test and the post-test as the system rapidly acquainting learners with lexicons and grammatical structures utilising educational 
games, interactive and engaging learning activities relating to four core skills of the English language from scratch until the completion of the assigned task. It proved to be a comprehensive solution contrasted with other web-based learning platforms and harmonised precisely with language learners' necessities and helped them increase confidence using a second language.

As for the results' worth, we are convinced that they provide evidence that can be useful for EFL educators in terms of using transmissive, interactive, and collaborative technological tools in English subjects at the university level. The present study highlights the effectiveness of technology tools, i.e., Transparent Language Online and Learning Management System, in teaching English receptive skills, i.e., reading and listening skills plus grammatical constructs and the use of English, to foreign language learners. This study's replication could provide further insights into the effects of the podcast, videocast, online tests, online glossary, and forums on other skills such as speaking and listening or other aspects such as vocabulary or culture.

Moreover, this study was directed explicitly at the university level in Pakistan to examine the efficacy of Transparent Language Online and increase students' confidence when interacting with such web-based platforms; nevertheless, similar studies may better measure such tools' efficacy and suitability at the K-12 sector. Besides, this inclusion helped English language instructors in enhancing their instructional approaches to plan, design, and implement technologydriven lessons to meet the emotional and learning needs of $21^{\text {st }}$-century learners. As a result, the findings validated the aim of this experiment. They proved the positive impact of focused technology tools that increased ELLs' performance on their academic assignments, increased their knowledge of the English language, and instilled confidence in using it in diverse environments.

\section{Limitation}

This pilot investigation, indeed, contains some limitations that might have affected the results. First, the study administered various assessments, pre-test, assessments, assignments, and post-test on LMS that could have impacted ELLs' academic performance and confidence due to technological and linguistic limitations. This experiment is further delimited to pre-test and post-test only and gauge ELLs' accomplishments on these tests. Second, the pilot treatment accentuated on a single group, the Faculty of Information Technology, and gathered data from the first-year computer science undergraduate population $(N=525)$, who were further restricted to two technology tools, Transparent LanguageOnline (TLO) and Learning Management System (LMS). TLO was used for content delivery, whereas assessments were administered in an observed synchronous environment on the university's LMS. Third, some instructors taught multiplesessions and ELLs' performance could have been affected due to financial constraints because of their biased approach or preconceived notions towards integrating advanced digital tools and web-based learning platforms in their lessons. Understanding the varied features of accessible digital tools would help illustrate more solid results, positively impact ELLs' academic accomplishment, and increase their confidence in using English at the tertiary level.

\section{Future Research}

The present findings of the experiment endorse some possible directions for future research on advanced technology tools and web-delivered learning platforms. First, the subjects in this exploration came from a computer science background; even in the first semester of their BS program, they had developed rudimentary comprehension of well-established technologies. Taking undergraduate students from other disciplines may improve our perception of how available digital tools being used for learning impact second language learners in general. English language learners, in particular, need further consideration. Besides, this pilot experiment was directed in one private sector university in Lahore, Pakistan; however, this venture could be extended to other public and private sector universities across the country that could help examine these tools' impact on ELLs and establish grounds for planned online teaching and pre-mediated for crisisprompted online education (Gacs et al., 2020). Finally, other variables affecting ELLs' performance and confidence could be investigated. What inspires and blocks ELLs to effectively utilise such tools to overcome technology affordances and enhance the integrated language skills.

\section{References}

Al Musawi, A. S. (2011). Redefining technology role in education. Creative Education, 2(02), 130. https://doi. org/10.4236/ce.2011.22018

Baran, E., Canbazoglu Bilici, S., Albayrak Sari, A., \& Tondeur, J. (2019). Investigating the impact of teacher education strategies on preservice teachers' TPACK. British Journal of Educational Technology, 50(1), 357-370. https://doi.org/10.1111/bjet.12565

Bonk, C. J., \& Graham, C. R. (2006). The handbook of blended learning: Global perspectives, local designs. John Wiley \& Sons.

Bonk, C. J., \& Wiley, D. A. (2020). Preface: Reflections on the waves of emerging learning technologies. Educational Technology Research and Development, 68(4), 1595-1612. https://doi. org/10.1007/s11423-020-09809-x

Bonner, E., \& Reinders, H. (2018). Augmented and virtual reality in the language classroom: Practical ideas. Teaching English with Technology, 18(3), 33-53.

Chapman, M., \& Newfields, T. (2008). The 'new' TOEIC. Shiken: JALT Testing \& Evaluation SIG Newsletter, 12(2), 32-37.

Chun, D., Kern, R., \& Smith, B. (2016). Technology in language use, language teaching, and language learning. The Modern Language Journal, 100(S1), 64-80. https://doi.org/10.1111/ $\underline{\operatorname{modl} .12302}$

Pegem Journal of Education and Instruction, ISSN 2146-0655 
Corder, G. W., \& Foreman, D. I. (2009). Non-parametric statistics for non-statisticians: A step-by-step approach. Wiley Publishing.

Creswell, J. W., \& Creswell, J. D. (2017). Research design: Qualitative, quantitative, and mixed methods approaches (5th ed.). Sage Publications. https://doi.org/10.1017/CBO9781107415324.004

DeMillo, R. A. (2019). Blended learning in practice: A guide for practitioners and researchers. In Bearbeitet von (pp. XVII-XX).

Dziuban, C., Graham, C. R., Moskal, P. D., Norberg, A., \& Sicilia, N. (2018). Blended learning: the new normal and emerging technologies. International Journal of Educational Technology in Higher Education, 15(1), 1-16. https://doi.org/10.1186/ $\underline{\mathrm{s} 41239-017-0087-5}$

Faul, F., Erdfelder, E., Lang, A. G., \& Buchner, A. (2007). G* Power 3: A flexible statistical power analysis program for the social, behavioral, and biomedical sciences. Behavior Research Methods, 39(2), 175-191.

Faul, F., Erdfelder, E., Buchner, A., \& Lang, A. G. (2009). Statistical power analyses using $\mathrm{G}^{*}$ Power 3.1: Tests for correlation and regression analyses. Behavior Research Methods, 41(4), 11491160. https://doi.org/10.3758/BRM.41.4.1149

Field, A., Miles, J., \& Field, Z. (2012). Discovering statistics using $R$. SAGE Publications.

Gacs, A., Goertler, S., \& Spasova, S. (2020). Planned online language education versus crisis-prompted online language teaching: Lessons for the future. Foreign Language Annals, 53(2), 380-392.

Godwin-Jones, R. (2017). Emerging technologies: Smartphones and language learning. Language Learning \& Technology, 21(2), 3-17.

Golonka, E. M., Bowles, A. R., Frank, V. M., Richardson, D. L., \& Freynik, S. (2014). Technologies for foreign language learning: A review of technology types and their effectiveness. Computer Assisted Language Learning, 27(1), 70-105. https://doi.org/10.1 $\underline{080 / 09588221.2012 .700315}$

Gunes, S. (2019). What are the perceptions of the students about asynchronous distance learning and blended learning? World Journal on Educational Technology: Current Issues, 13(4), 230-237.

Horn, M. B., \& Staker, H. (2017). Blended: Using disruptive innovation to improve schools. John Wiley \& Sons.

Kessler, G. (2018). Technology and the future of language teaching. Foreign Language Annals, 51(1), 205-218. https://doi. org/10.1111/flan.12318

Ko, M. H. (2017). Learner perspectives regarding device type in technology-assisted language learning. Computer Assisted Language Learning, 30(8), 844-863. https://doi.org/10.1080/0 $\underline{9588221.2017 .1367310}$

Koehler, M. J., Mishra, P., \& Cain, W. (2013). What is technological pedagogical content knowledge (TPACK)? Journal of Education, 193(3), 13-19. https://doi.org/10.1177/002205741319300303

Larson-Hall, J. (2015). A guide to doing statistics in second language research using SPSS and $R$. Routledge.

Laurillard, D. (2013). Rethinking university teaching: A conversational framework for the effective use of learning technologies. Routledge.
Leedy, P. D., \& Ormrod, J. E. (2016). Practical research: Planning and design (11th ed.). Pearson.

Levy, M. (2009). Technologies in use for second language learning. The Modern Language Journal, 93(769-782).

Lin, J. J., \& Lin, H. (2019). Mobile-assisted ESL/EFL vocabulary learning: A systematic review and meta-analysis. Computer Assisted Language Learning, 32(8), 878-919. https://doi.org/1 $\underline{0.1080 / 09588221.2018 .1541359}$

Loewen, S., Crowther, D., Isbell, D. R., Kim, K. M., Maloney, J., Miller, Z. F., \& Rawal, H. (2019). Mobile-assisted language learning: A Duolingo case study. ReCALL, 31(3), 293-311. https://doi org/10.1017/S0958344019000065

Loewen, S., Isbell, D. R., \& Sporn, Z. (2020). The effectiveness of appbased language instruction for developing receptive linguistic knowledge and oral communicative ability. Foreign Language Annals, 53(2), 209-233. https://doi.org/10.1111/flan.12454

Loewen, S., \& Plonsky, L. (2015). An A-Z of applied linguistics research methods. Macmillan International Higher Education.

Lupton, D., Mewburn, I., \& Thomson, P. (2018). The digital academic: Critical perspectives on digital technologies in higher education. Routledge.

Madden, A. G., Margulieux, L., Kadel, R. S., \& Goel, A. K. (2019). Blended learning in practice: A guide for practitioners and researchers. The MIT Press.

McCarthy, M. (Ed.). (2016). The Cambridge guide to blended learning for language teaching. Cambridge University Press.

Mishra, P., \& Koehler, M. J. (2006). Technological pedagogical content knowledge: A framework for teacher knowledge. Teachers College Record, 108(6), 1017-1054.

$\mathrm{Ng}$, W. (2015). New digital technology in education: Conceptualizing professional learning for educators. Springer. https://doi. org/10.1007/s10758-015-9267-3

Ortega, L. (2017). New CALL-SLA research interfaces for the 21st century: Towards equitable multilingualism. CALICO Journal, 34(3), 285-316. https://doi.org/10.1558/cj.33855

Özyurt, Ö., \& Özyurt, H. (2017). A qualitative study about enriching programming and algorithm teaching with flipped classroom approach. Pegem Journal of Education and Instruction, 7(2), 189. https://doi.org/10.14527/pegegog.2017.007

Parmaxi, A. (2020). Virtual reality in language learning: A systematic review and implications for research and practice. Interactive Learning Environments, 1-13. https://doi.org/10.1080/104948 $\underline{20.2020 .1765392}$

Plonsky, L. (2015). Advancing quantitative methods in second language research. Routledge.

Powers, D. E., Kim, H.-J., \& Weng, V. Z. (2008). The redesigned Toeicl (listening and reading) test: Relations to test-taker perceptions of proficiency in English. ETS Research Report Series, 2008(2), i-120. https://doi.org/10.1002/j.2333-8504.2008.tb02142.x

Quraishi, N. H., Asif, M., Sheeraz, M., \& Amer, K. (2020). Novel coronavirus (COVID-19) and its impact on education at tertiary level: Challenges and solutions for Pakistani universities. Journal of Education \& Social Sciences, 8(2), 40-54. https://doi. org/10.20547/jess0822008204 
Riazi, A. M. (2016). The Routledge encyclopedia of research methods in applied linguistics. Routledge. https://doi.org/10.4324/9781315656762

Rosenberg, J. M., \& Koehler, M. J. (2015). Context and technological pedagogical content knowledge (TPACK): A systematic review. Journal of Research on Technology in Education, 47(3), 186-210. https://doi.org/10.1080/15391523.2015.1052663

Salehudin, M. (2021). Extending Indonesia government policy for e-learning and social media usage. Pegem Journal of Education and Instruction, 11(2), 14-26. https://doi.org/10.14527/ pegegog.2021.02

Selwyn, N. (2013). Education in a digital world: Global perspectives on technology and education. Routledge.

Shehzadi, S., Nisar, Q. A., Hussain, M. S., Basheer, M. F., Hameed, W. U., \& Chaudhry, N. I. (2020). The role of digital learning toward students' satisfaction and university brand image at educational institutes of Pakistan: a post-effect of COVID19. Asian Education and Development Studies. https://doi. org/10.1108/AEDS-04-2020-0063

Steel, C. H., \& Levy, M. (2013). Language students and their technologies: Charting the evolution 2006-2011. ReCALL, 25(3), $306-320$. https://doi.org/10.1017/S095834401 3000128
Stein, J., \& Graham, C. R. (2014). Essentials for blended learning: A standards-based guide. Routledge. https://doi. org/10.4324/9781351043991

Suzuki, M., \& Daza, C. (2004). A review of the reading section of the TOEIC. TESL Canada Journal, 16-24.

Ullman, M. T. (2001). The neural basis of lexicon and grammar in first and second language: The declaratice/procedural model Bilingualism: Language and Cognition, 4(2), 105-122. https:// doi.org/10.1017/s1366728901000220

Vesselinov, R., Grego, J., Sacco, S. J., \& Tasseva-Kurktchieva, M. (2019). The 2019 Rosetta Stone efficacy study. http:// comparelanguageapps.com/documentation/The2019_RS_ FinalReport.pdf

Wilson, K. M. (2000). An exploratory dimensionality assessment of the TOEIC test. ETS Research Report Series, 2000(2), i-28. https://doi.org/10.1002/j.2333-8504.2000.tb01837.x

Yang, Y. F., \& Kuo, N. C. (2020). New teaching strategies from student teachers' pedagogical conceptual change in CALL. System, 90(123), 102218. https://doi.org/10.1016/j.system.2020.102218

Zar, J. H. (2014). Spearman rank correlation: Overview. Encyclopedia of Biostatistics, 1-9. https://doi.org/10.1002/9781118445112. stat05964 